\title{
EESTI VOKAALIKATEGOORIATE PIIRID VENE JA EESTI EMAKEELEGA KÕNELEJATE TAJURUUMIS
}

\section{Lya Meister}

\begin{abstract}
Ülevaade. Vaatluse all on eesti ja vene emakeelega keelejuhtide eesti vokaalikategooriate taju. Töös püstitatud hüpoteeside kohaselt tajuvad vene emakeelega kuulajad eesti vokaale /i/, /e/, /u/, /o/, /a/ ja /ä/ sarnaselt eesti keelejuhtidega - vokaalikategooriate piirid on mõlema rühma puhul lähedased. Probleemiks on aga vene häälikusüsteemi jaoks võõraste eesti vokaalikategooriate /ü/, /ö/ ja /õ/ eristamine, sest need on foneetiliselt lähedased vene /õ/-le. Tajukatse tarvis sünteesiti neljaformandilised eesti vokaaliprototüübid ja vahepealse kvaliteediga stiimulid, muutes formantsageduste väärtusi kindla sammuga, nii et saadud stiimulijada moodustas vokaaliprototüüpide vahelises ruumis diskreetse rastri (16-18 stiimulit iga vokaalipaari vahel, kokku 14 vokaalipaari). Stiimulid esitati kuulajatele juhuslikus järjekorras ja neil tuli otsustada, millist vokaali kahest võimalikust nad tajusid. Eksperimendi tulemused andsid kinnitust püstitatud hüpoteesidele.*
\end{abstract}

Võtmesõnad: kategoriaalne taju, vokaal, kategooria piir, K1, K2, eesti keel, vene keel

\section{Sissejuhatus}

Reeglina on täiskasvanud võõrkeeleõppijal raskusi õpitava keele häälikute perfektse omandamisega nii häälduse kui taju tasemel - tulemuseks on sihtkeele tüüpilisest hääldusest hälbiv kõne, mida sihtkeele sünnipärased kõnelejad tajuvad aktsendina. Üldtunnustatud seisukoha järgi on võõrkeelse aktsendi peamiseks põhjuseks imikueas omandatud emakeelsed hääldus- ja tajumallid (Polivanov 1931, Trubetzkoy 1939, Lado 1957, Lenneberg 1967, Selinker 1972, Kuhl 1991, Best 1994, Flege 1995, Major 2001 jt).

* Artikkel on valminud riikliku programmi “Eesti keele keeletehnoloogiline tugi" ja sihtfinantseeritava teema 
Esimese eluaasta jooksul omandab laps oma emakeele põhilised fonoloogilised kategooriad (Cheour jt 1998) ja õpib segmenteerima pidevat kõnesignaali diskreetseteks segmentideks - vokaalideks ning konsonantideks. Eksperimentaalsed uuringud on näidanud, et vokaalikategooriad kujunevad välja esimese 6 kuu jooksul (Kuhl jt 1992, Polka, Werker 1994), konsonantide kategooriad aga 10-12 kuu vanuselt (Werker, Tees 1984). Emakeele häälikumallide omandamise järel kurdistub lapse kõnetaju emakeeles mitte-esinevate kategooriate suhtes. See nn "fonoloogiline kurtus" on püsiv ja põhjustab raskusi võõrkeeles esinevate kontrastide tajumisel ning võõrkeele häälduse omandamisel (Dupoux, Peperkamp 2002). Fonoloogiline kurtus on määratud eelkõige emakeele fonoloogilise süsteemiga, see ilmneb erinevate võõrkeelte puhul erinevalt (sõltuvalt võoorkeele fonoloogilisest süsteemist) ja võib esineda nii segmentaalsete kui ka prosoodiliste kategooriate tajumisel. Mõned näited: 1) jaapanlastel on raskusi eristada inglise keele foneeme /r/ ja /l/ (Yamada 1995, jt), sest jaapani keeles on ainult üks liikvida - /r/, mis kuuldeliselt on lähedasem pigem inglise /l/-le kui /r/-le (Takagi 1993); 2) hispaania emakeelega kõnelejad ei erista inglise vokaalfoneeme /i/ ja /I/ ning vastendavad neile hispaania keele /i/-vokaali (Flege 1991); 3) kontrastiivne kestus (lühikestepikkade foneemide vastandus) on omane kvantiteedi-keeltele, näiteks jaapani, eesti ja soome keelele, kuid kestusvastandust ei esine näiteks prantsuse, vene ja hispaania keeles; 4) rõhu akustilisteks korrelaatideks on valjus, põhitooni sagedus ja kestus (Lehiste 1970), kuid mitte kõik keeled ei kasuta neid tunnuseid rõhu väljendamiseks - kontrastiivse kestusega keeltes ei ole kestus rõhu korrelaadiks (Hayes 1995), näiteks eesti keeles on rõhk seotud valjuse ja põhitooniga, kuid vene keeles eelkõige kestusega (Bondarko 1977).

Võõrkeele häälikusüsteemi omandamine on otseselt seotud kõnetajuga ja sõltub sellest, kui lähedastena tajutakse emakeele ning sihtkeele akustiliselt ja artikulatoorselt sarnaseid häälikuid, ehk teisiti öeldes, kui suur on tajutud foneetiline kaugus emakeele ja sihtkeele vastenduvate üksuste vahel. Kõnetaju rolli võõrkeele fonoloogiliste kategooriate omandamisel käsitlevad kaks teoreetilist mudelit: pertseptiivse assimilatsiooni mudel (ingl Perceptual Assimilation Model - PAM) (Best 1994) ja kõne õppimise mudel (ingl Speech Learning Model - SLM) (Flege 1995). Kuigi nimetatud mudelid lähtuvad kõnekommunikatsiooni erinevatest aspektidest, sõltub mõlema mudeli kohaselt võoorkeele häälikusüsteemi omandamise edukus emakeele (K1) ja võõrkeele (K2) üksuste foneetilise kauguse tajust: 1) akustiliselt ja pertseptiivselt lähedasi K2 kategooriaid on raske eristada ja need assimileeruvad vastava(te) K1 kategooria(te)ga; 2) K1 kategooriast akustiliselt ja pertseptiivselt erineva K2 häälikuklassi jaoks luuakse uus kategooria.

Töös uuritakse vene emakeelega eesti keelt võõrkeelena kõnelevate isikute eesti vokaalikategooriate taju, lähtudes eelnimetatud teoreetilistest mudelitest. Tajukatsetes kasutatakse sünteesitud stiimuleid, mis hõlmavad kõigi eesti vokaalikategooriate piire. Vene emakeelega kuulajate testitulemusi hinnatakse võrdluses eesti keelt emakeelena kõnelejate kategooriapiiridega. 


\section{Eesti vs. vene vokaaliruum}

Akustilises ruumis kirjeldatakse vokaale nelja esimese formandi (F1-F4) sagedusega hertsides, kuid olulisemad vokaali kvaliteedi määramisel on kaks esimest formanti.

Vokaalide artikulatoorseteks tunnusteks on keele kõrgus, keele ees/tagapoolsus ja huulte ümardatus. Eesti keeles eristatakse kolme keele kõrgusastet: [kõrge], [keskkõrge] ja [madal], kolme positsiooni ees-taga dimensioonis: [ees], [kesk] ja [taga] ning binaarset huulte ümardatuse tunnust [ \pm ümar] (Eek 2008). Artikulatoorsed ja akustilised tunnused on omavahel seotud järgmiselt: F1 sagedus on seotud keele kõrgusega - mida madalam on keele asend, seda kõrgem on F1 sagedus; F2 sagedus korreleerub keele tagapoolsuse tunnusega - mida eespoolsem, seda kõrgem on F2 sagedus; F3 sageduse alusel on võimalik eristada ümardatud ja ümardamata eesvokaale - ümardatud vokaalide F3 sagedus on madalam. F4-l ei ole vokaali artikulatoorsete tunnustega otsest seost, tegemist on kõnetrakti resonantssagedusega, mis mõjutab kõneleja isikupärast kõnetämbrit.

Eesti keeles on üheksa vokaalfoneemi, mis binaarsete artikulatoorsete tunnuste alusel klassifitseeritakse järgmiselt (Eek 2008).

Tabel 1. Eesti keele üheksa vokaalfoneemi artikulatoorsed tunnused

\begin{tabular}{|l|c|c|c|c|c|c|c|c|c|c|c|}
\hline & $I$ & $\mathbf{i}$ & $\ddot{\mathbf{u}}$ & $\mathbf{e}$ & $\ddot{\mathbf{o}}$ & $\ddot{\mathbf{a}}$ & $\mathbf{0}$ & $\mathbf{o}$ & $\mathbf{u}$ & $\mathbf{a}$ & $I$ \\
\hline [taga] & & - & - & - & - & - & + & + & + & + & \\
\hline [madal] & & & & - & - & + & - & - & & + & \\
\hline [ümar] & & - & + & - & + & & - & + & + & & \\
\hline [kõrge] & & + & + & - & - & & & - & + & & \\
\hline
\end{tabular}

Vene keeles on 6 vokaali, mis keele kõrgusastme järgi jagunevad kõrgeteks - /i, u, ô/, keskkõrgeteks - /e, o/ ja madalaks /a/; häälduskoha paiknemise järgi eestaga dimensioonis jagunevad need eesvokaalideks /i, e/ ja tagavokaalideks /u, o/. Raskusi on /a/ ja /õ/ määratlemisega - neid klassifitseeritakse kui keskvokaale või siis nii ees- kui tagavokaalide hulka kuuluvateks (Ljubimova 1977: 24). Ainsa madala vokaalina on /a/ häälduskoht varieeruv, realiseerudes foneetilisest kontekstist sõltuvalt erinevate allofoonidena, näiteks palataliseeritud konsonantide vahel kui [æ] - сядь [s'æt'] 'istu', enne palataliseeritud konsonanti kui [a] - дams [dat'] 'andma' või palataliseerimata konsonandi järel kui [a], kui talle järgneb [t] палка [połk^] 'kepp' (Bondarko jt 200o: 26-28). Arikulatoorselt on vene /a/ siiski lähedasem taga- kui eesvokaalidele, seetõttu klassifitseeritakse seda valdavalt tagavokaaliks (Bondarko 1977: 80).

Sarnaselt /a/-ga esineb vene /õ/ erinevate allofoonidena sõltuvalt naaberkonsonantide artikulatoorsetest tunnustest, lisaks iseloomustab teda keeleasendi muutus vokaali häälduse jooksul keskmisest positsioonist eespoolsemaks, mistõttu kuuldub vokaal pigem diftongina /õi/. Tüüpiliselt realiseerub vene /õ/ keskvokaalina [i] - ты [ti] 'sina', velaarklusiilide ja postalveolaarsete frikatiivide naabruses aga tagavokaalina - шишка [ $\int \mathrm{i} \int \mathrm{k} \Lambda$ ] 'käbi' (Bondarko jt 2000: 28). Et vene /õ/ on artikulatoorselt lähedasem pigem /u/-le kui /i/-le, siis klassifitseeritakse teda kui ettepoole nihutatud tagavokaali (Ljubimova 1977: 27-28). 
Vene emakeelega kõnelejate eestikeelse kõne uuringud on näidanud, et vene aktsendi sagedaseks tunnuseks on hälbed eesti vokaalide hääldamisel (L. Meister 2005). Et hääldus on otseselt seotud kõnetajuga, siis võib oletada, et uuritud K2 kõnelejad ei ole piisavalt hästi omandanud eesti keele vokaalikategooriaid. Kinnitust sellele oletusele annavad uurimistulemused, mille kohaselt K2 taju areng on eelduseks K2 kategooriate korrektsele hääldamisele (Flege 1993, Llisterri 1995). Samuti on leitud, et väljakujunenud K2 tajumallide puhul on K2 hääldamine täpsem ja seetõttu pakub K2 tajukategooriate testimine hea võimaluse hääldusraskuste prognoosimiseks (Barry 1989).

Vene emakeelega kõneleja jaoks on uuteks fonoloogilisteks kategooriateks eesti vokaalid /ü/, /ö/, /ä/ ja osaliselt ka /õ/, nende produktsioonis esinesid ulatuslikumad hälbed eelkõige /ü/, /ö/ ja /õ/ korral; vokaalid /i/, /e/, /u/, /o/ ja /a/ on mõlemas keeles suhteliselt lähedase kvaliteediga, nende puhul langes K2 kõnelejate hääldus üsna hästi kokku eesti keelejuhtide häl̈ldusega (L. Meister 2005). Kuidas seletada K2 kõnelejate hääldusvariatsioone ja millised hüpoteesid on otstarbekas püstitada eesti vokaalikategooriate tajueksperimendiks?

Lähtudes PAM ja SLM mudelitest võib püstitada järgmised hüpoteesid.

1. Foneetiline kaugus eesti ja neile vastenduvate vene vokaalide /i/, /e/, /u/ $\mathrm{ja} / \mathrm{o} /$ vahel on väike ning seetõttu assimileeruvad eesti vokaalid vastavate vene vokaalidega:

$\begin{array}{lll}\text { eesti } & & \text { vene } \\ \text { /i/ } & \rightarrow & / \mathrm{i} / \\ \mathrm{e} / & \rightarrow & / \mathrm{e} / \\ \mathrm{u} / & \rightarrow & / \mathrm{u} / \\ \mathrm{lo} / & \rightarrow & \mathrm{o} /\end{array}$

2. /a/ on vene vokaaliruumis ainus madal vokaal, vastav piirkond eesti vokaaliruumis on jagatud vokaalide /a/ ja /æ/ vahel, seega on tegemist binaarse kontrastiga:

$$
\begin{array}{lll}
\text { eesti } & & \text { vene } \\
/ \mathrm{a} / & \text { y } & \\
/ \mathfrak{x} / & \nearrow & \mathrm{a} /
\end{array}
$$

Kahe kategooria vastendumine K2 hälikusüsteemis ühele kategooriale emakeeles tekitab suuri probleeme K2 kategooriate eristamisel, näiteks on jaapanlastel raske tajuda inglise keele $/ \mathrm{l} / \mathrm{ja} / \mathrm{r} /$ kategooriate erinevust. Olukord on tõenäoliselt erinev vene-eesti madalate vokaalide korral - et vene vokaal /a/ realiseerub kontekstist sõltuvalt [æ] või [a] allofoonina, siis ei ole vastavate eesti vokaalide kvaliteedi kontrast vene emakeelega kuulajale võõras ja kategooriate eristamine kujuneb lihtsaks. Seda prognoosib ka SLM teooria hüpotees, mille kohaselt K1 ja K2 häälikud suhtestuvad teineteisega allofoonilisel tasemel, mitte abstraktsete foneemide tasemel (Flege 1995). Foneetiline kaugus vene allofoonide ja vastavate eesti vokaalikategooriate vahel on väike ning seetõttu võib oodata eesti vokaalide assimileerumist vastavate vene vokaalivariantidega:

$$
\begin{array}{lll}
\text { eesti } & & \text { vene } \\
/ \mathrm{a} / & \rightarrow & {[\mathrm{a}]} \\
/ æ / & \rightarrow & {[æ]}
\end{array}
$$


3. Eesti vokaalide $/ \mathrm{y} /, / \varnothing / \mathrm{ja} / \mathrm{\gamma} /$ lähimaks vasteks on vene vokaal /i/, seega on tegemist mitme kategooria assimilatsiooniga:

$\begin{array}{lll}\text { eesti } & & \text { vene } \\ / \mathrm{y} / & \mathrm{y} & \\ / \varnothing / & \rightarrow & / \mathrm{i} / \\ \mid \gamma / & \pi & \end{array}$

Foneetiline kaugus vastenduvate vokaalide vahel on suhteliselt väike, mistõttu on nende pertseptiivne eristamine ja seega ka uute kategooriate tekkimine K2 tajuruumis raskendatud.

4. Kui uued vokaalikategooriad on kõneleja K2 tajuruumis kinnistunud, siis on nende piirid lähedased eesti emakeelega keelejuhtide vastavate piiridega; kui kategooriad on alles kujunemisfaasis, siis on nende piirid hägusad.

\section{Metoodika}

Igale abstraktsele vokaalikategooriale vastendub akustilises ruumis mingi formantsagedustega F1-F4 määratletav piirkond, mille keskpunktis paikneb vastava vokaali prototüüp. Et vokaalid oleksid kuuldeliselt hästi eristatavad, paiknevad vokaalid akustilises ruumis üksteisest võrdsetel kaugustel (Liljencrants, Lindblom 1972). Kui vokaalisüsteemi lisandub uus vokaal, siis põhjustab see vokaalipiiride ümberjaotuse kogu süsteemis - nii peab näiteks eesti keelt õppiv vene emakeelega kõneleja "mahutama" seni kuue vokaali vahel jaotunud ruumi kolm uut vokaali. See saab toimuda ainult vanade kategooriapiiride ümberpaigutuse teel.

Vokaalikategooria piiridele vastavate formantsageduste väärtuste leidmiseks kasutatakse tüüpiliselt metoodikat, mille raames viiakse läbi tajukatsed sünteesitud vokaalidega. Vokaalide formantsageduste väärtusi on muudetud kindla sammuga, nii et saadud stiimulijada moodustab kogu akustilist ruumi katva rastri. Näiteks eesti vokaalide sihtväärtuste ja vokaalipiiride leidmisel kasutati kaheformandilisi sünteesvokaale, mille puhul formantide väärtusi muudeti sammuga o,33 barki (Eek, E. Meister 1994). Analoogses Turu ülikooli vokaalitestis kasutati kolmeformandiseid stiimuleid, mille puhul F1 sammuks oli 30 melli, F2 sammuks 40 melli ja F3 muudeti 200 melli kaupa (Raimo, Savela, Aaltonen 2002). Stiimulite sünteesiks kasutatakse tüüpiliselt Klatt’i formantsünteesi mudelit (Klatt 1980).

Stiimulid esitatakse keelejuhtidele vokaalipaaride kaupa juhuslikus järjekorras ja kuulajate ülesandeks on iga stiimuli kohta märkida, kas nad kuulevad vokaali X või vokaali Y. Tegemist on kategoriaalse taju testiga, kus stiimuleid, mille formandiväärtused varieeruvad ühe kategooria piires, tajutakse valdavalt vokaalina X (vt joonis 1, stiimulid 1-6) või vokaalina Y (vt joonis 1, stiimulid 10-16), kategooriapiiri ümbruses jaotuvad tajuotsustused kahe kategooria vahel. Tulemusena saadakse tajukõver (vt joonis 1), kus kategooria piirina defineeritakse stiimul, mille puhul kahe kategooria tajuskoor on võrdne $(0,5)$, piirialasse kuuluvaks defineeritakse tüüpiliselt stiimulid, mille puhul tajuskoor on vahemikus $0,25-0,75$. 


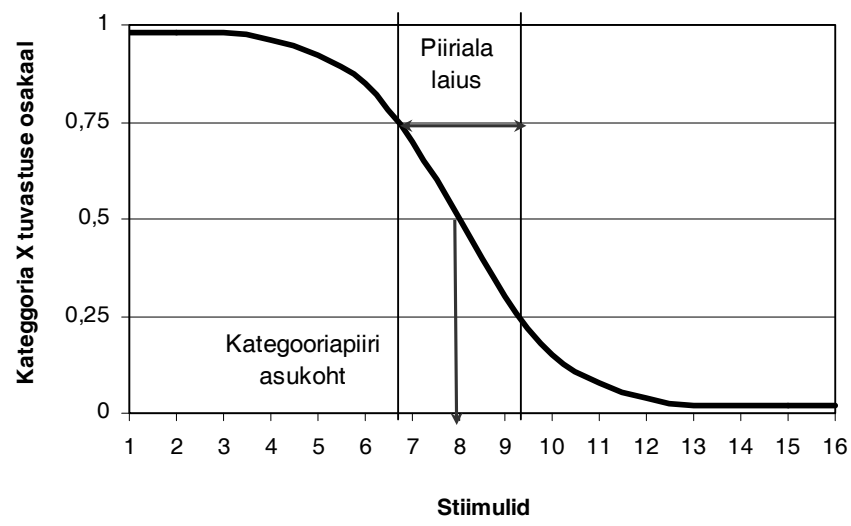

Joonis 1. Kategooriatesti tajukõver

Järgnevalt kirjeldatava katse tulemusena saadakse K1 ja K2 keelejuhtide vokaalikategooriate tajuskoorid, eelkõige pakuvad huvi kategooriapiiri asukoht ja piiriala laius K1 ja K2 keelejuhtide võrdluses.

\subsection{Stiimulikorpus}

Stiimulikorpuse sünteesil võeti vokaaliprototüüpide aluseks isoleeritult hääldatud eesti vokaalide formantsageduste mõõteandmed (kuue meeskõneleja keskmised) (Liiv, Remmel 1970), sest vokaalitüüpi esindavad paremini just hüperartikuleeritud vokaalid (Eek, E. Meister 1994). ${ }^{1}$ Vokaaliprototüüpide sünteesiks kasutati tarkvarapaketti KlattWorks (tuntud Klatt'i mudeli realisatsioon) (McMurray, ilmumas). Sünteesi käigus kohandati (ümardati edasiste arvutuste lihtsustamiseks) mõningaid formandiväärtusi ja lõplikud neljaformandilised vokaaliprototüübid sünteesiti tabelis 2 toodud formandisagedustega.

Tabel 2. Sünteesitud vokaaliprototüüpide formandisagedused hertsides

\begin{tabular}{|l|c|c|c|c|c|c|c|c|c|}
\hline & /i/ & /e/ & /ä/ & /ü/ & $/ \mathbf{o} /$ & $/ \tilde{o} /$ & $/ \mathbf{u} /$ & $/ \mathbf{o} /$ & /a/ \\
\hline F1 & 250 & 400 & 670 & 260 & 410 & 380 & 300 & 450 & 650 \\
\hline F2 & 2220 & 1950 & 1550 & 1750 & 1550 & 1150 & 660 & 800 & 1000 \\
\hline F3 & 3000 & 2580 & 2400 & 2200 & 2400 & 2160 & 2250 & 2460 & 2250 \\
\hline F4 & 3430 & 3350 & 3400 & 3220 & 3220 & 3220 & 3220 & 3300 & 3220 \\
\hline
\end{tabular}

Järgnevalt sünteesiti baasvokaalidevahelised stiimulijadad (vt joonis 2) - igas jadas 16 kuni 18 stiimulit - muutes sammhaaval formantväärtusi F1-F4 $(\Delta \mathrm{F} 1=1-16 \mathrm{~Hz}$, $\Delta \mathrm{F} 2=0-30 \mathrm{~Hz}, \Delta \mathrm{F} 3=0-50 \mathrm{~Hz}, \Delta \mathrm{F}_{4}=0-15 \mathrm{~Hz}$ sõltuvalt vokaalipaarist), koos baasvokaalidega kokku 243 stiimulit. Iga stiimuli kestus on $160 \mathrm{~ms}$ ja põhitooni sagedus $120 \mathrm{~Hz}$. 


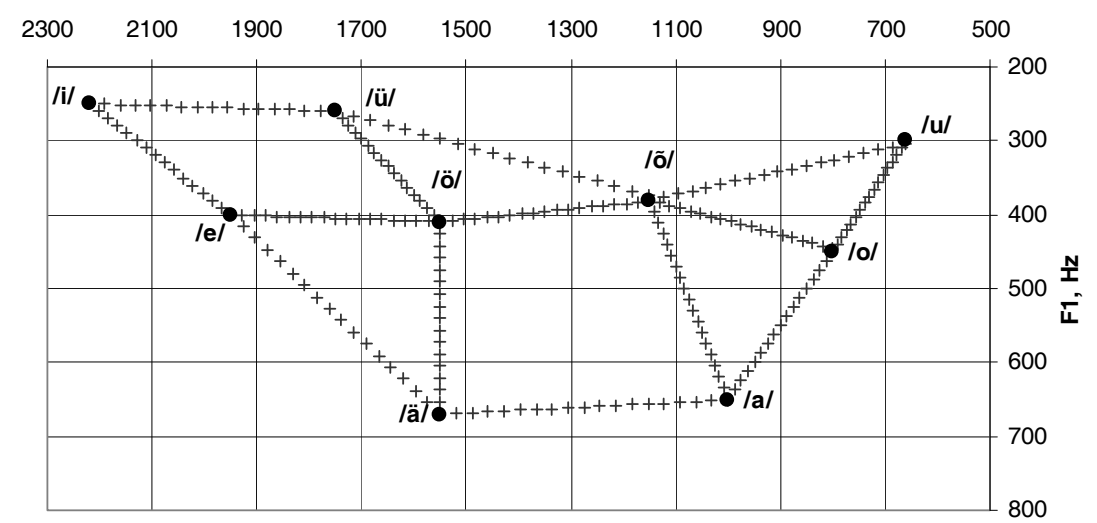

Joonis 2. Baasvokaalid (•) ja nendevahelised stiimulid (+) akustilises ruumis

\subsection{Tajukatse}

Tajukatseks kasutati eksperimendikeskkonda Praat (Boersma, Weenink 2008). Katse sisaldas 14 katseseeriat (14 vokaalipaari, 16-18 stiimulit igas jadas); iga stiimul kordus testis juhuslikus järjekorras kolm korda, seega esitati kuulajale hindamiseks kokku 729 stiimulit. Katseisikule esitati küsimus "Kas kuuldud häälik on V1 või V2?”, kus V1 ja V2 on vastava vokaalipaari vokaalid. Tegemist oli sundvalikuga, kus tajuotsustus tuli teha kahe alternatiivi vahel. Test viidi läbi müravabas ruumis, stiimulid esitati kuulajatele arvutist läbi kõrgekvaliteediliste kõrvaklappide, katse kestus oli $\mathrm{ca} 20$ minutit.

Katseisikutena osalesid 5 eesti emakeelega ( 2 meest, 3 naist) ja 9 vene emakeelega (4 meest, 5 naist) isikut vanuses 20 kuni 52 aastat, kõik kõrgharidusega. K2 keelejuhid oskasid eesti keelt kesk- või kõrgtasemel, kuuldelise hinnangu põhjal oli nende kõnes tajutav nõrk kuni keskmine aktsent; eesti keelt hakkasid nad õppima vanuses 3 kuni 20 aastat.

\section{Tulemused}

Katsetulemuste töötlemisel arvutati K1 ja K2 gruppide keskmine tajuskoor iga stiimuli kohta, kusjuures välja jäeti üksikud selgelt hälbivad juhuslikud tajuotsustused (näiteks kui vokaaliprototüübile A lähedaste stiimulite korral tajuti vokaali B. Kategooriapiiri asukohaks defineeriti stiimul, mille tajuskoor oli kõige lähem väärtusele 0,5 ; piiriala laius määrati tajuskoori väärtuste 0,25 ja 0,75 vahele jäävate stiimulite arvuga. Tajukatse tulemused on esitatud kokkuvõtvalt tabelis 3, kus on toodud ka piiri asukohale vastava stiimuli formandiväärtused F1 ja F2 ning piiriala laius hertsides. Joonisel 3 on esitatud baasvokaalid koos K1 ja K2 keelejuhtide tajutud vokaalikategooriate piirialadega. 
Tabel 3. K1 ja K2 keelejuhtide tajutud vokaalikategooriate piirid ja piiriala laiused

\begin{tabular}{|c|c|c|c|c|c|c|c|c|c|c|c|c|c|}
\hline \multirow[b]{3}{*}{$\begin{array}{l}\text { Vokaali- } \\
\text { grupp }\end{array}$} & \multirow[b]{3}{*}{$\begin{array}{c}\text { Stiimuli- } \\
\text { jada }\end{array}$} & \multicolumn{6}{|c|}{ K1 piir } & \multicolumn{6}{|c|}{ K2 piir } \\
\hline & & \multicolumn{3}{|c|}{ Asukoht } & \multicolumn{3}{|c|}{ Laius } & \multicolumn{3}{|c|}{ Asukoht } & \multirow{2}{*}{\begin{tabular}{|c|} 
Laius \\
$\begin{array}{c}\text { Stiimulite } \\
\text { arv }\end{array}$ \\
\end{tabular}} & \multirow[b]{2}{*}{$\mathrm{F} 1$} & \multirow[b]{2}{*}{$\mathrm{F} 2$} \\
\hline & & $\begin{array}{l}\text { Stiimuli } \\
\text { number }\end{array}$ & $\mathrm{F} 1$ & F2 & $\begin{array}{c}\text { Stiimulite } \\
\text { arv }\end{array}$ & $\mathrm{F} 1$ & F2 & $\begin{array}{l}\text { Stiimuli } \\
\text { number }\end{array}$ & $\mathrm{F} 1$ & $\mathrm{~F} 2$ & & & \\
\hline \multirow{2}{*}{ la } & $a-a ̈$ & 10 & 661 & 1275 & 2 & 2 & 61 & 10 & 661 & 1275 & 2 & 2 & 61 \\
\hline & a-o & 8 & 538 & 888 & 1 & 13 & 13 & 8 & 538 & 888 & 1 & 13 & 13 \\
\hline \multirow{3}{*}{$\mathrm{Ib}$} & i-ü & 8 & 254 & 2014 & 2 & 1 & 59 & 9 & 255 & 1985 & 2 & 1 & 59 \\
\hline & ö-ä & 10 & 556 & 1550 & 2 & 32 & 0 & 11 & 573 & 1550 & 2 & 32 & 0 \\
\hline & u-o & 9 & 375 & 730 & 2 & 19 & 18 & 10 & 384 & 739 & 2 & 28 & 26 \\
\hline \multirow{4}{*}{ Ic } & õ-u & 9 & 346 & 932 & 2 & 8 & 54 & 9 & 346 & 932 & 3 & 13 & 82 \\
\hline & i-e & 8 & 320 & 2094 & 2 & 20 & 36 & 8 & 320 & 2094 & 3 & 30 & 54 \\
\hline & õ-a & 10 & 515 & 1075 & 2 & 30 & 17 & 10 & 515 & 1075 & 3 & 45 & 25 \\
\hline & e-ä & 11 & 559 & 1715 & 2 & 32 & 47 & 11 & 559 & 1715 & 3 & 48 & 71 \\
\hline \multirow{2}{*}{ II } & õ-o & 9 & 409 & 994 & 3 & 11 & 58 & 10 & 413 & 975 & 4 & 15 & 78 \\
\hline & e-ö & 8 & 404 & 1794 & 2 & 1 & 44 & 7 & 403 & 1817 & 3 & 2 & 67 \\
\hline \multirow{3}{*}{ II } & õ-ü & 9 & 311 & 1483 & 3 & 19 & 100 & 8 & 304 & 1517 & 5 & 32 & 167 \\
\hline & ö-ü & 9 & 335 & 1650 & 3 & 28 & 38 & 8 & 326 & 1663 & 5 & 47 & 63 \\
\hline & õ-ö & 9 & 401 & 1417 & 3 & 5 & 67 & 7 & 397 & 1372 & 5 & 8 & 111 \\
\hline
\end{tabular}

F2, Hz

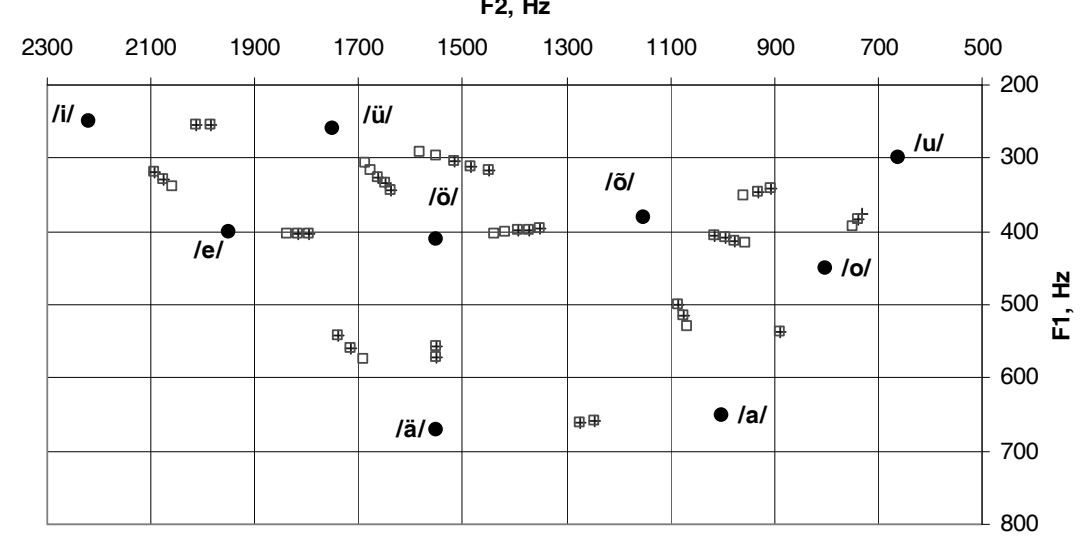

Joonis 3. Baasvokaalid $(\bullet)$ ning $\mathrm{K} 1(+)$ ja $\mathrm{K} 2(\square)$ keelejuhtide tajutud vokaalikategooriate piirialad

Tabelis 3 on stiimulijadad jagatud kahte gruppi sõltuvalt K1 ja K2 keelejuhtide tulemuste võrdlusest. I grupi moodustavad stiimulijadad (vt joonis 4), mille puhul K1 ja K2 tulemused langevad kokku või siis erinevad ühe stiimulisammu võrra, jäädes loomuliku variatiivsuse piiridesse. See grupp on omakorda jagatud järgmisteks alamgruppideks: Ia - K1 ja K2 tajutud kategooriapiirid ning piiri laiused on identsed; Ib - K1 ja K2 piiriala laius on võrdne, kuid piiri asukoht on nihkes ühe stiimulisammu võrra; Ic - K1 ja K2 kategooriapiirid langevad kokku, kuid K2 piiriala on laiem; Id - K1 ja K2 piirid erinevad ühe stiimuli võrra ja piiriala laius on K2 tajuruumis suurem. 
la: K1 ja K2 tajutud kategooriapiirid ning piiri laiused on võrdsed
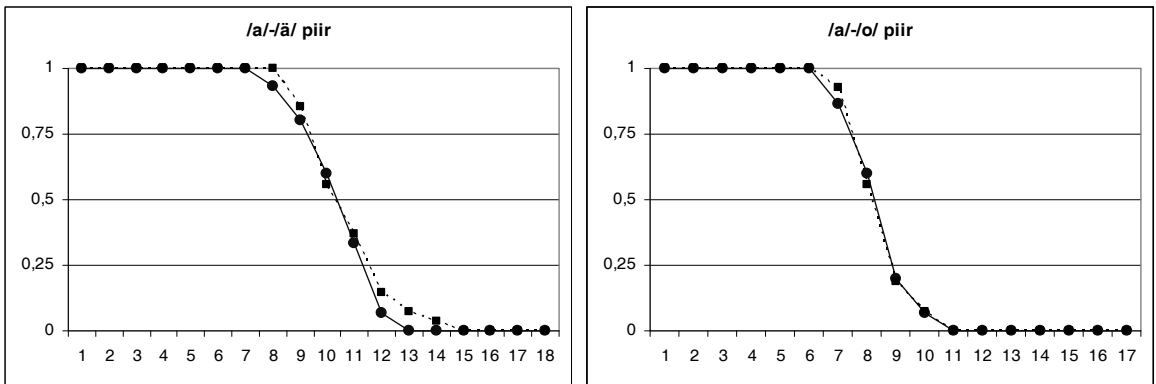

Ib: K1 ja K2 piiriala laius on võrdne, piiri asukoht on nihkes ühe stiimulisammu võrra
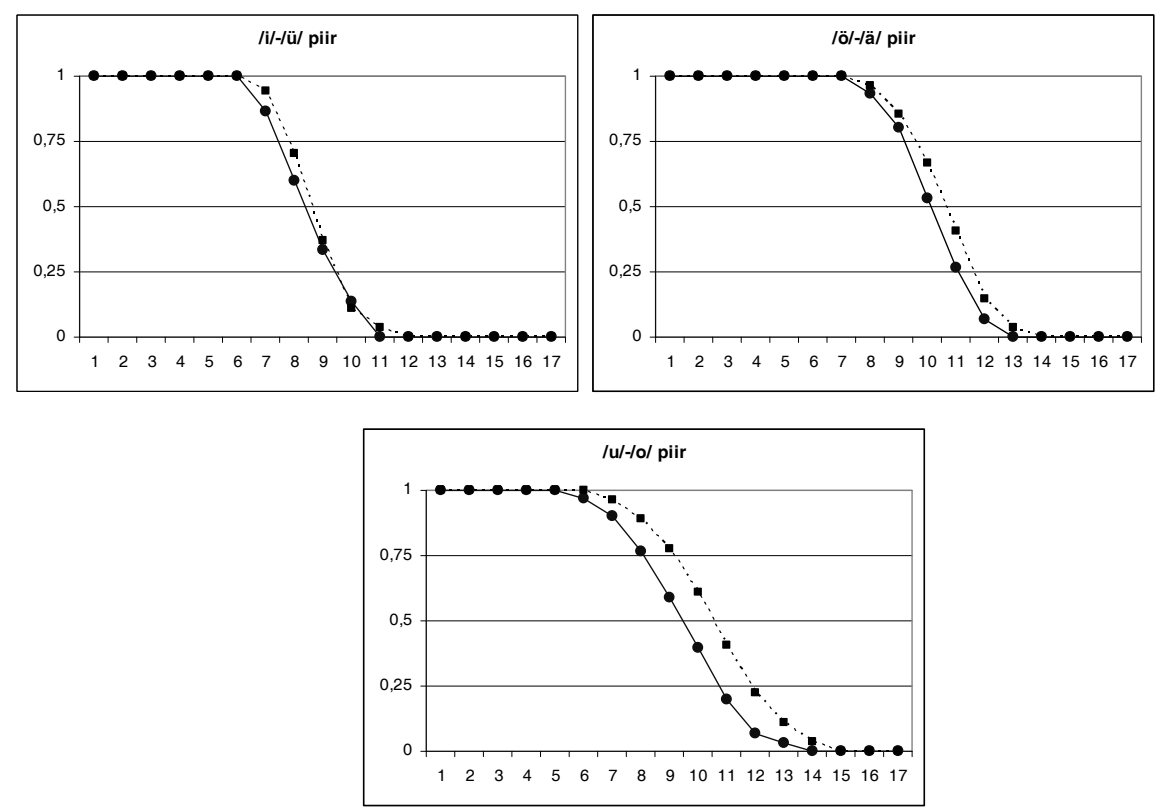

Ic: $\mathrm{K} 1$ piir = K2 piir, K2 piiriala on laiem
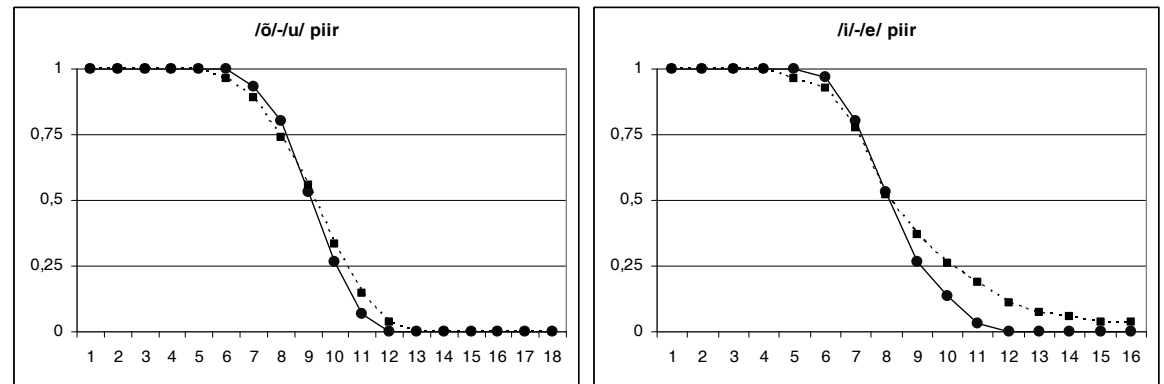

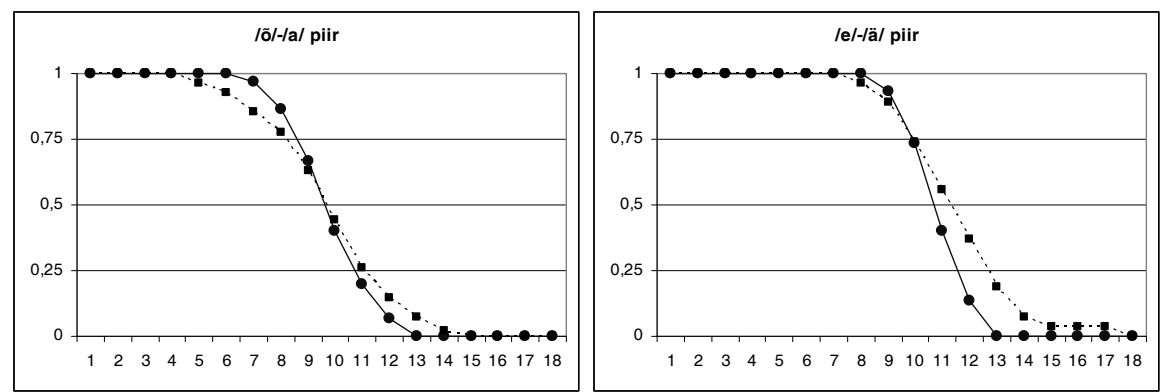

Id: K1 ja K2 piirid erinevad, K2 piiriala laius on suurem
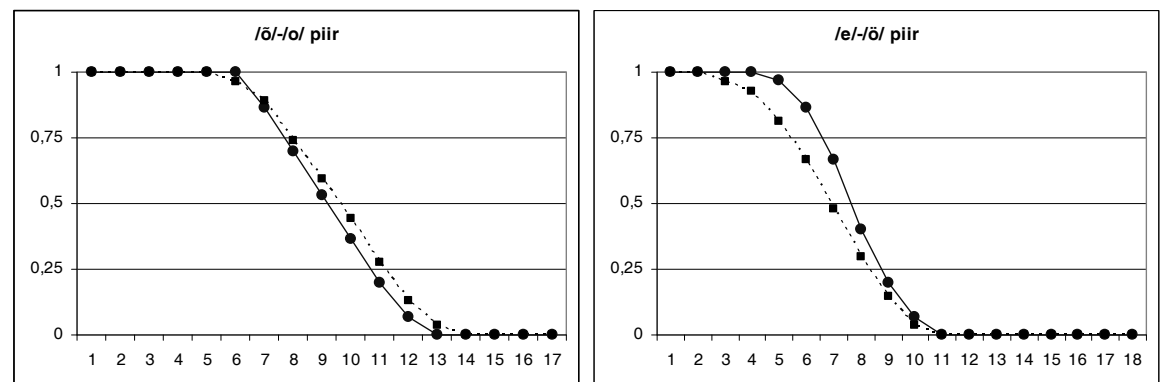

Joonis 4. K1 (•, pidevjoon) ja K2 (•, punktiirjoon) keelejuhtide tajukõverad vokaaligruppide la, Ib, Ic, Id stiimulijadade korral. Vertikaalteljel tajuskoor, horisontaalteljel stiimulite numbrid

II gruppi liigitati need stiimulijadad, mille puhul K1 ja K2 testitulemused on selgelt erinevad - tajutud kategooriapiirid ei lange kokku ning piiriala laiused on K2 tajuruumis tunduvalt suuremad (vt joonis 5).
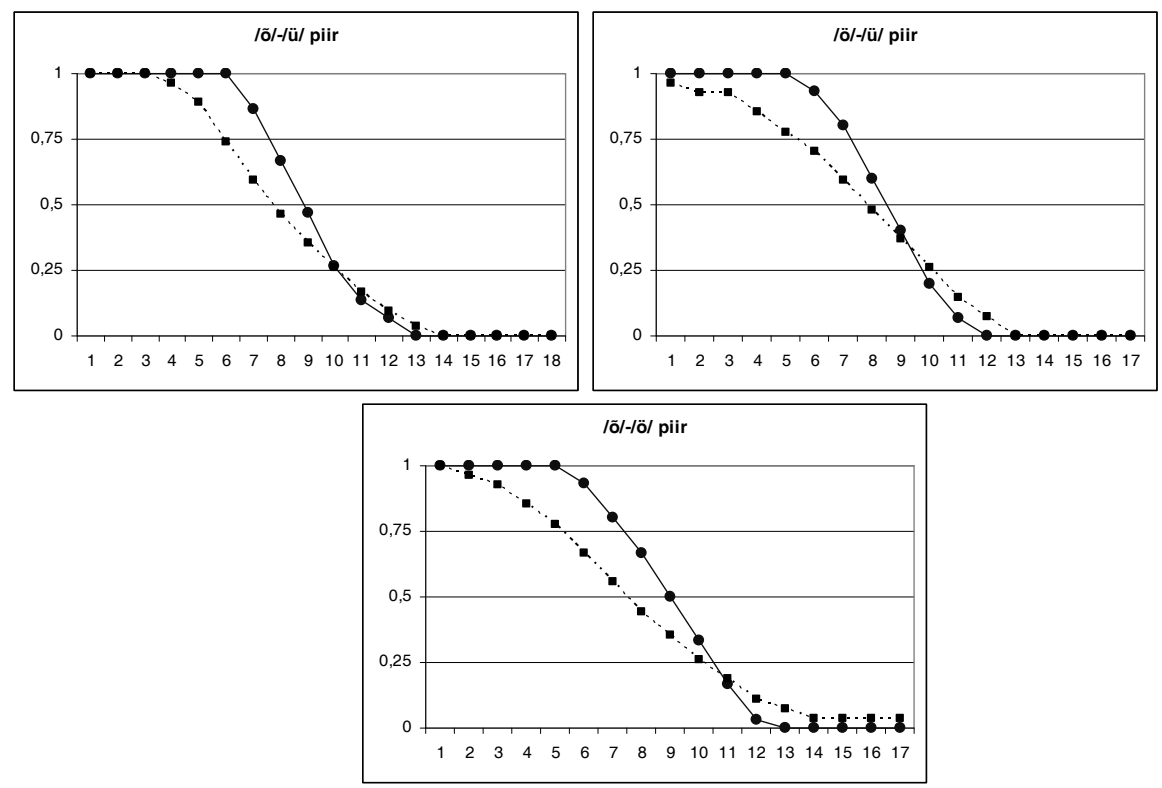

Joonis 5. K1 (•, pidevjoon) ja K2 (•, punktiirjoon) keelejuhtide tajukõverad II vokaaligrupi 
Tajutesti tulemused annavad kinnitust töös püstitatud hüpoteesidele.

1) Foneetiline kaugus eesti ja neile vastenduvate vene vokaalide /i/, /e/, /u/ $\mathrm{ja} / \mathrm{o} /$ vahel on väike ning seetõttu assimileeruvad eesti vokaalid vastavate vene vokaalidega. K2 keelejuhid tajusid vokaalide /i/, /e/, /u/ ja /o/ kategooriapiire oma lähinaabritega sarnaselt K1 keelejuhtidega: /i/-/e/ piir K1 ja K2 puhul paiknes samas kohas, K2 puhul oli piiriala pisut laiem; /u/-/o/ piir oli K2 tajuruumis pisut nihutatud /o/ suunas, piiriala laius oli mõlemal juhul sama. Piiride hälbed teiste naabervokaalidega (/i/-/ü/ja /o/-/a/)jäid samuti ühe stiimulisammu piiresse.

2) Foneetiline kaugus vene vokaalfoneemi /a/ allofoonide [a] ja [æ] ning vastavate eesti vokaalikategooriate /a/ ja /ä/ vahel on väike, assimileerumine leiab aset allofoonilisel tasandil. K2 keelejuhtide tajutulemused eesti /a/-/ä/ kategooriate eristamisel on lausa identsed K1 rühma tulemustega, sama tulemus saadi vokaalipaari /a/-/o/ puhul; K2 ja K1 rühmade tulemused teiste naaberkategooriate (/a/-/õo/, /ä/-/ö/ ja /ä/-/e/) piiride tajumisel erinevad minimaalselt.

3) Eesti vokaalide /ü/, /ö/ ja /õ/lähimaks vasteks on vene vokaal/i/. Foneetiline kaugus vastenduvate vokaalide vahel on suhteliselt väike, mistõttu on nende pertseptiivne eristamine ja uute kategooriate tekkimine K2 tajuruumis raskendatud - tulemustest nähtub, et K2 rühma /ü/-/ö/-/õ/ kategooriapiirid on laiemad ja piiri asukoht erinev võrreldes K1 rühmaga. Eelkõige on probleemiks uute kategooriapiiride asetus nimetatud vokaalide vahelises "siseruumis", sest K2 kategooriapiirid "välisnaabritega" (/u/, /o/, /a/, /ä/, /e/ ja /i/) on hästi paigas ja hälbivad minimaalselt K1 vastavatest piiridest.

4) K2 tajuruumis kinnistunud vokaalikategooriate piirid on lähedased K1 keelejuhtide vastavate piiridega; kujunemisfaasis kategooriate piirid on hägusad - eesti vokaalikategooriate /i/, /e/, /u/, /o/ ja /ä/ piirid langevad K2 ja K1 rühmade puhul hästi kokku, s.t neid eristatakse lähedaselt eesti emakeelega kuulajatega. Võib järeldada, et nende vokaalikategooriate omandamine ei valmista K2 rühmale erilisi probleeme. K2 kategooriapiirid on hägusad uute vokaalikategooriate / ̈̈/, /ö/ ja /õ/ puhul, nende kvaliteedierinevuste taju ja seetõttu ka produktsioon on vene emakeelega kuulajatele probleemiks.

\section{Kokkuvõtteks}

Tajukatsed näitasid, et 1) eesti vokaalide /i, e, u, o, a, ä/ kategooriapiire tajuvad vene emakeelega keelejuhid sarnaselt eestlastega, kuid 2) vokaalide /ü, ö, õ/ piirid on K2 tajuruumis tunduvalt hägusamad. Esimesel juhul on tegemist eesti vokaalikategooriate assimileerumisega akustiliselt ja pertseptiivselt lähedaste vene vokaalivariantidega, teisel juhul on tegemist vene vokaalisüsteemi jaoks uute kategooriatega, mis osaliselt assimileeruvad vene /õ/-vokaaliga. See, et uute vokaalikategooriate piirid K2 tajuruumis hälbivad vastavatest K1 piiridest, näitab, et need kategooriad ei ole omandatud emakeelega võrdsel tasemel. Saadud eksperimenditulemused on kooskõlas tuntud aktsenditeooriatega (SLM ja PAM). 


\section{Viidatud kirjandus}

Barry, William 1989. Perception and production of English vowels by German learners: Instrumental-phonetic support in language teaching. - Phonetica, 46, 155-168.

Best, Catherine T. 1994. The emergence of native-language phonological influence in infants: A perceptual assimilation model. - J. Goodman, H. Nusbaum (Eds.). The Development of Speech Perception: The Transition from Speech Sounds to Spoken Words. Cambridge, MA: MIT Press, 167-224.

Boersma, Paul; Weenink, David 2008. Praat: doing phonetics by computer. Version 5.0.36. Computer program. http://www.praat.org/ (20.07.2008).

Bondarko 1977 = Бондарко, Л. В. 1977. Звуковой строй современного русского языка. Москва: Просвещение.

Bondarko jt 2000 = Бондарко, Л. В.; Вербицкая, Л. А.; Гордина, М. В. 2000. Основы общей фонетики. Санкт-Петербург: Филологический факультет СанктПетербургского государственного университета.

Cheour, Marie; Ceponiene, Rita; Lehtokoski, Anne; Luuk, Aavo; Allik, Jüri; Alho, Kimmo; Näätänen, Risto 1998. Development of language-specific phoneme representations in the infant brain. - Nature Neuroscience, 1, 351-353. doi:10.1038/1561

Dupoux, Emmanuel; Peperkamp, Sharon 2002. Fossil markers of language development: phonological deafnesses in adult speech processing. - B. Laks, J. Durand (Eds.). Phonetics, Phonology, and Cognition. Oxford: Oxford University Press, 168-190.

Hayes, Bruce 1995. Metrical Stress Theory: Principles and Case Studies. Chicago, London: The University of Chicago Press.

Eek, Arvo; Meister, Einar 1994. Eesti vokaalide sihtväärtused hääldus- ja tajuruumis. - Keel ja Kirjandus, 7, 404-413; 8, 476-483; 9, 548-553.

Eek, Arvo; Meister, Einar 1998. Quality of Standard Estonian vowels in stressed and unstressed syllables of the feet in three distinctive quantity degrees. - Linguistica Uralica, 34 (3), 226-233.

Eek, Arvo 2008. Eesti keele foneetika I. Tallinn: TTÜ Kirjastus.

Flege, James E. 1991. The interlingual identification of Spanish and English vowels: Orthographic evidence. - Quarterly Journal of Experimental Psychology, 43A, 701-731.

Flege, James E. 1993. Production and perception of a novel, second-language phonetic contrast. - Journal of the Acoustical Society of America, 93, 1589-1608. doi:10.1121/1.406818

Flege, James E. 1995. Second language speech learning: Theory, findings, and problems. W. Strange (Ed.). Speech Perception and Linguistic Experience: Issues in GrossLanguage Research. Timonium: York Press, 233-275.

Klatt, Dennis H. 1980. Software for a Cascade/Parallel Synthesizer. - Journal of the Acoustical Society of America, 67, 971-995. doi:10.1121/1.383940

Kuhl, Patricia K. 1991. Human adults and human infants show a "perceptual magnet effect" for the prototypes of speech categories, monkeys do not. - Perception \& Psychophysics, 50, 93-107.

Kuhl, Patricia K.; Williams, Karen A.; Lacerda, Francisco; Stevens, Kenneth N.; Lindblom, Bjorn 1992. Linguistic experience alters phonetic perception in infants by six months of age. - Science, 255/5044, 606-608. doi:10.1126/science.1736364

Lado, Robert 1957. Linguistics across Cultures: Applied Linguistics for Language Teachers. Ann Arbor: University of Michigan Press.

Lehiste, Ilse 1970. Suprasegmentals. Cambridge MA, London: The MIT Press.

Lenneberg, Eric H. 1967. The Biological Foundation of Language. New York: John Wiley.

Liiv, Georg; Remmel, Mart 1970. On acoustic distinctions in the Estonian vowel system. Soviet Fenno-Ugric Studies, 1, 7-23.

Liljencrants, J.; Lindblom, B. 1972. Numerical simulation of vowel quality systems: the role of perceptual contrast. - Language, 48 (4), 839-862. doi:10.2307/411991 
Ljubimova 1977 = Любимова, Н. А. 1977. Обучение русскому произношению. Москва: Русский язык.

Llisterri, Joaquim 1995. Relationships between speech production and speech perception in a second language. - K. Elenius, P. Branderud (Eds.). Proceedings of the XIIIth International Congress of Phonetic Sciences. Vol 4. Stockholm, Sweden, 13-19 August 1995. Stockholm: KTH / Stockholm University, 92-99.

Major, Roy C. 2001. Foreign Accent: The Ontogeny and Phylogeny of Second Language Phonology. Mahwah, New Jersey, London: Lawrence Erlbaum Associates Publishers.

McMurray, Bob (ilmumas). KlattWorks: A [somewhat] new systematic approach to formantbased speech synthesis for empirical research.

Meister, Lya 2005. Vene aktsent eesti keeles. Akustiline analüüs. Magistritöö. Tallinn: Tallinna Pedagoogikaülikool.

Polivanov, E. D. 1931. La perception des sons d'une langue étrangère. - Travaux du Cercle linguistique de Prague, 4, 79-96.

Polka, Linda; Werker, Janet F. 1994. Developmental changes in perception of non-native vowel contrasts. - Journal of Experimental Psychology: Human Perception and Performance, 20, 421-435. doi:10.1037/0096-1523.20.2.421

Raimo, Ilkka; Savela, Janne; Aaltonen, Olli 2002. The Turku vowel test. - P. Korhonen (Ed.). Fonetiikan Päivät 2002. The Phonetics Symposium 2002. Helsinki University of Technology, Laboratory of Acoustics and Audio Signal Processing. Report 67. Espoo, 45-52.

Selinker, Larry 1972. Interlanguage. - International Review of Applied Linguistics, 10, 209-231.

Takagi, Naoyuki 1993. Perception of American English /r/ and /l/ by Adult Japanese Learners of English: A Unified View. PhD. dissertation. University of California, Irvine.

Trubetzkoy, N. S. 1939. Grundzüge der Phonologie. - Traveaux de Cercle Linguistique de Prague, 7, 272.

Werker, Janet F.; Tees, Richard C. 1984. Cross-language speech perception: evidence for perceptual reorganization during the first year of life. - Infant Behavior and Development, 7, 49-63. doi:10.1016/So163-6383(84)80022-3

Yamada, Reiko A. 1995. Age and acquisition of second language speech sounds perception of American English /x/ and /l/ by native speakers of Japanese. - W. Strange (Ed.). Speech Perception and Linguistic Experience: Issues in Gross-Language Research. Timonium: York Press, 305-320.

Lya Meister (Tallinna Tehnikaülikooli Küberneetika Instituudi foneetika ja kõnetehnoloogia laboratoorium). Uurimisvaldkonnad on kõne analüüs, eksperimentaalfoneetika, võõrkeelne aktsent, kõnekorpused.

lya@phon.ioc.ee 


\section{ESTONIAN VOWEL CATEGORY BOUNDARIES IN THE PERCEPTION SPACE OF RUSSIAN AND ESTONIAN SUBJECTS}

\section{Lya Meister}

Tallinn University of Technology

Adult second language (L2) learners often face difficulties in the pronunciation and perception of L2 speech segments. It is mainly due to the so-called phonological deafness towards certain phonetic contrasts of L2, which develops after the acquisition of a child's first language (L1) phonetic inventory during its early years of life. The ability to perceive and distinguish L2 sounds depends on the phonetic distance between similar segments in L1 and L2.

The aim of the study is to test the perception of Estonian vowel categories by L2 learners of Estonian whose L1 is Russian. Estonian vowel system includes nine vowels whereas Russian has only six. Five of the Estonian vowels, /i/, /e/, /u/, /o/ and /a/, have their counterparts in Russian; the new vowel categories are /ü/, /ö/, /ä/, and partly /õ/.

Four hypotheses were posed:

1. The Estonian vowels /i/, /e/, /u/ and /o/ will assimilate well with their Russian counterparts as their phonetic distance is close.

2. The Estonian /a/ and /ä/ will assimilate with the corresponding allophones in Russian.

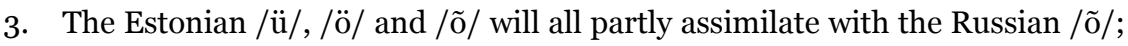
due to their close phonetic distance the ability of discrimination of these three categories is poor.

4. The boundaries of well-established vowel categories are similar for both L1 and L2 subjects, the boundaries of new vowel categories, if not acquired yet, are rather fuzzy.

For the perceptual experiments four-formant vowel stimuli were synthesized including nine Estonian prototype vowels and intermediate steps (16 to 18 steps) between the prototypes. The stimuli set covered 14 vowel-pairs (vowel category boundaries); the duration of a single stimulus was $160 \mathrm{~ms}$, the stimuli were played three times in random order, while the listeners had to answer the question "Did you hear vowel X or vowel Y?" by clicking the corresponding character on a computer screen. Five ( 2 male, 3 female) native Estonian subjects and nine (4 male, 5 female) non-native (Russian as L1) ones were involved in the experiment. All L2 subjects had low or mid-level foreign accent, their knowledge of Estonian was reported from average to high.

Based on the perception results the location and the width of the vowel category boundaries were found for the L1 and the L2 subjects. The results of the perception tests confirm our hypotheses: L2 subjects perceive Estonian vowels /i/, /e/, /u/, /o/, /a/ and /ä/ similarly as L1 subjects - just minor differences in the location and width of the vowel boundaries were found; whereas the boundaries of new vowel categories / ̈̈/, /ö/ and /õ/ deviate significantly in L2 subjects from those of L1 subjects. The findings presented in the paper are in good harmony with accent theories such as Perceptual Assimilation Model (PAM) (Best 1994) and Speech Learning Model (SLM) (Flege 1995).

Keywords: categorical perception, vowel, category boundary, L1, L2, Estonian, Rus- 